\title{
Application of Blockchain Technology in the Sharing Economy: A Model of Trust and Intermediation
}

\author{
Pascal Mehrwald \\ Technical University \\ of Munich \\ pascal.mehrwald@tum.de
}

\author{
Theresa Treffers \\ Technical University \\ of Munich \\ theresa.treffers@tum.de
}

\author{
Maximilian Titze \\ Technical University \\ of Munich \\ maximilian.titze@tum.de
}

\author{
Isabell M. Welpe \\ Technical University \\ of Munich \\ welpe@tum.de
}

\begin{abstract}
Combining blockchain technology and smart contracts has the potential to facilitate disintermediation and realize true peer-to-peer transactions provided that sufficient trust is build. An advanced research model of blockchain-mediated trust is conceptualized by incorporating extant trust building concepts. The conceptualized model helps to advance future empirical trust research in connection with blockchain technology in the sharing economy by suggesting moderating and mediating effects on trust in online settings.
\end{abstract}

\section{Introduction}

Blockchain technology in combination with smart contracts has the potential to take over the roles of intermediaries and realize direct peer-to-peer transactions in the sharing economy. Technically, this would be possible and has been widely mentioned in literature [29, 83]. Disintermediation by blockchain technology poses a substantial threat to incumbent platform organizations like Uber, Airbnb, Amazon or Facebook. In a peer-to-peer sharing economy based on the new technology, markets and hierarchies would blend and transaction costs could be strongly reduced. Nevertheless, replacing organizational tasks with a new technology requires trust.

Trust has been widely studied in the context of ecommerce by Gefen, Benbasat, and Pavlou [35], McKnight, Choudhury, \& Kacma [63], Gefen [36], Pavlou \& Gefen [74]. Research has focused on intermediated, business-to-consumer transactions, neglecting disintermediated peer-to-peer transactions. However, it is important to study trust in disintermediated peer-to-peer transactions because it offers enormous potential for disruption of existing markets, organizations and the way transactions are realized.
Therefore, studying how the introduction of blockchain technology for activities in the sharing economy would affect peoples' trust-related behavior or intention to transact [36, 44, 62] can help organizations assess the potential and the possible impact on existing business models. Also, empirically studying blockchain technology's actual chance of acceptance among end-users as a replacement for intermediaries poses a promising research opportunity. This is promising, because established trust concepts lack to address disintermediation possibilities by blockchain technology to replace organizations. The presence of blockchain technology in the trust building process needs to be incorporated in existing trust concepts because of its high potential to affect trust and transactions in online markets. These transactions may be peer-to-peer, human-to-machine or machine-tomachine interactions, which are expected to become increasingly important.

The paper aims to fill this gap by conceptualizing a model of blockchain-mediated trust of peer-to-peer transactions in the sharing economy. In our model, we build on existing trust research in e-commerce and conceptualize an advanced trust model where blockchain technology can be applied to increase trust among peers in the sharing economy, decrease intermediation and reduce transaction costs.

Our study aims to make the following contributions. First, it offers a conceptual framework for future empirical studies that seek to study how blockchain technology affects trust in the sharing economy. Second, our model allows existing intermediaries to infer strategic implications in face of a possible disruption. Third, as suggested by the research agenda for trust in online environments by Gefen, Benbasat, \& Pavlou [35], our study allows us to further examine dimensionalities and moderators of trustworthiness and trust in online settings as well as advance the relationship between trust and information technology. 


\section{Sharing economy and lateral exchange markets}

First mentioned by Lessig [53], the term "sharing economy" in its most recent meaning was initially referred to as an act of "collaborative consumption" which was characterized by sharing, exchanging and renting of assets without actually owning them. With the utilization of web 2.0 technologies, the idea of sharing as an ancient social practice has been turned into a booming economic practice, which is today widely known as the sharing economy [11]. As an oxymoron, the sharing economy links directly opposed terms regarding human relationships and behavior by merging sharing as an act of distributing owned assets to others and economy as a system of trade and industry to generate and utilize wealth [10, 43]. Because the sharing economy still lacks a precise and commonly accepted definition, we follow Perren and Kozinets' [75] broader conceptualization of the phenomenon and develop a typology of peer-to-peer markets, referring to them as manifestations of lateral exchange markets. Lateral exchange market can be defined as "[...] a market that is formed through an intermediating technology platform that facilitates exchange activities among a network of equivalently positioned economic actors." [75].

\section{Trust in online peer-to-peer transactions}

\subsection{Trust concepts in online markets}

Studies investigating online trust are typically based on established works of McKnight, Choudhury, and Kacmar [62]; McKnight et al. [63]. This study follows Gefen \& Straub [36] and Gefen [32]' conceptualization of trust because it has been suggested in the business-to-consumer e-commerce context. This framework (Figure 1) differentiates between the antecedents of trust, institution-based trust, cognitive trusting beliefs and behavioral trusting intentions, or trust-related behavior. Behavioral trusting intentions are general and non-committal, whereas trust-related behavior is specific and bears risks for the trustor [63]. Trust-related behaviors are actual activities (e.g. making a purchase) that represent dependency on the trustee, thereby increasing the risk and vulnerability of the trustor [58,93]. In line with McKnight et al. [62], behavioral trusting intentions are used as a measurement of subject behavior. Behavioral trusting intentions are measured by two sub-constructs, namely willingness to depend and subjective probability of depending [62]. This approach is common when examining trust, due to the strong correlations between trust-related behavior and behavioral trusting intentions $[1,49,62,88]$. In this paper, trust represents a context-dependent social concept, whose multidimensional attributes depend on the environment of the interactions, covering cognitive elements as well as behavioral intentions [17, 31, 64].

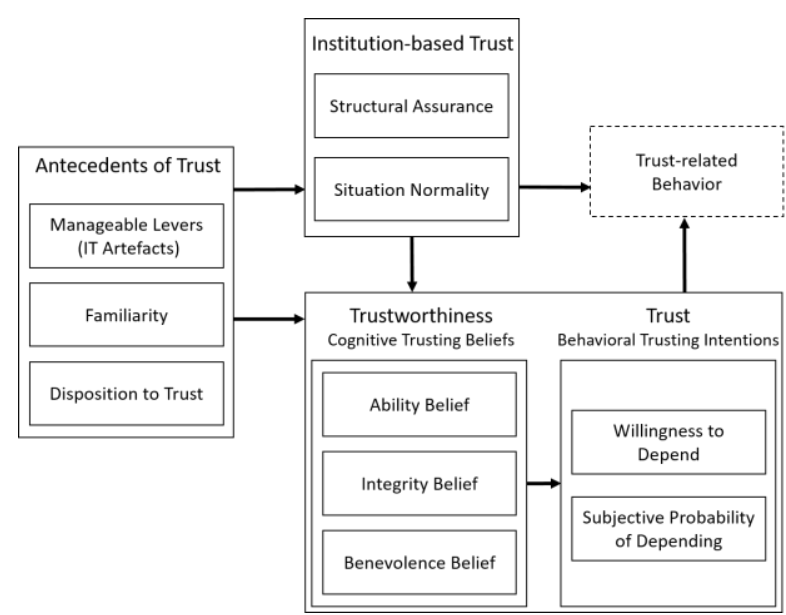

Figure 1. Trust concepts in online-transactions

Cognitive trusting beliefs (cognitive elements) relate to trustworthiness, while behavioral trusting intentions (behavioral intentions) relate to trust. Trustworthiness represents cognitive characteristics beliefs - of trust, which determine the context-related beliefs of the trustor about the trustee acting ethically and having attributes that are beneficial to the trustor. It provides the initial setting and justification for possible intended behavior. Given Trustworthiness, trust represents behavioral intentions of an individual that would increase the vulnerability to other parties on the conditions of interdependence and vulnerability. $[14,26,47,58,60,62,73,74,77,79]$.

Titled as the currency of peer-to-peer markets, trust was identified as a crucial driver for participation, long-term success and satisfaction of transactions [20, $45,65,82]$. As most transactions only occur once between the same parties in lateral exchange markets, the existence of trust has been found to be significantly important [36, 75]. This is due to the increasing transaction complexity of socially distant relationships as well as the rising dependency on other entities and their possible misconduct in online markets [38]. Hence, trust is regarded as the most effective complexity- and vulnerability-reduction mechanism transactions in lateral exchange markets [24, 56].

Literature also suggest that antecedent factors, including manageable levers (IT artefacts), trust disposition and familiarity with the service or products, influence the creation of trust [32, 35, 61, 62] Trust disposition refers to one's faith in humanity as well as 
their trusting stance. Familiarity clarifies what the trustor expects of the trustee based on past interactions between the two. Also, when the trustor is significantly familiar with the context, that experience will positively impact institutional-based trust [62]. Trust building levers can be understood as signals or symbols when the parties are still unfamiliar with each other. IT-artefacts might help build trust in online transactions [62, 64].

Transactions in the sharing economy typically involve a triad of interactions, including peers (consumers and providers), the platform and the shared product, resulting in trust being based on interpersonal and platform-mediated relationships that develop into a radius of trust $[46,66,67,90]$. This triad allows for the identification of different trust relationships. At the same time, however, its entanglement of entities also leads to blurred lines between the involved parties, resulting in "firm-market hybrids" [83] with high levels of perceived complexity $[66,67]$.

The three targets of trust have also been distinguished into trust in peers, trust in the platform and trust in the product as well as their respective influence on intention to transact as the resulting behavioral trusting intention [46]. This distinction is mainly based on the logic that human behavior in online environments is influenced by multiple trust targets on two-sided markets, namely trust in the platform and trust in peers [19, 52, 54, 59, 72, 74]. As a result, the latter distinction extends traditional trust research from business-to-consumer e-commerce, where trust is directed only towards the vendor in form of dependency during the transaction, while trust among peers is not evident in traditional models (see $[32,36,63,67])$.

\subsection{Trust in peers}

Trust (behavioral intention) is increased if the trustee shows indicators that allow the trustor to develop the willingness to depend on the trustee [14, 56, 62]. In online transactions, there are two ways how trust is established among parties [36]: Constructive interaction or interpersonal behaviors and cues that indicate trustworthiness. In line with current research [35], trustworthiness will be referred to as trust in this paper.

Trust in the peer is based on the peer-to-peer concept of the sharing economy, resulting in private peers taking on the roles of customer and vendor [46]. Trust used to be bestowed to close friends or family only, representing social capital as trusted relations and interactions among homogeneous communities, based on shared norms and identities [22, 76]. Within the sharing economy, however, trust is given to unfamiliar peers, which are part of networks on platforms. This interpersonal trust forms the core of trust in the sharing economy, since activities on platforms are identified by high consociality (social factor among peers) and their corresponding relationships of the acting peers on the platform [66, 67, 75].

To more deeply grasp trust of the peer and its effect on intention to interact, we argue along trustworthiness' three distinct dimensions of ability, benevolence and integrity [14, 31, 34, 35, 56, 58, 62, $66,78]$. Accordingly, trust in the peer can be described whether the supplying peer has the necessary ability to perform his side of the transaction in question and whether he can be considered as a transaction party of high integrity and benevolence [44, 73]. Furthermore, the ability dimension is referring to the trustee's relevant competencies and characteristics for the task at hand, such as driving skills for ride-hailing services [67]. A supplying peer with high level of integrity and benevolence could still lack the ability to fulfil the task in an appropriate manner.

Benevolence within trust in peers refers to the perception of the supplying peer's intention to keep the consumer's interest in mind, such as providing a great accommodation experience for the guest rather than having sole profit making in mind [67]. Integrity and benevolence of the supplying peer are of great importance in the context of the sharing economy, due to the vulnerable position to opportunistic behavior the customer is put into, since she or he is strongly dependent on desirable behavior of the supplying peer $[44,50]$.

The dimension integrity generally answers the question whether the supplying peer's principles are acceptable for the consuming peer [46]. Integrity might include the fact whether the supplying peer keeps his word and whether the resulting actions are in line with promises made, for example, if the accommodation has the promised condition and quality [67]. Most consuming peers do not have any prior credible, meaningful information about the supplying peer, because parties often change with every transaction, resulting in significant importance of initial trust and opportunistic behavior [13]. Initial trust refers to the trust when parties first meet, online or offline [64]. Opportunistic betrayal is composed of benevolence and integrity, describing the likelihood, that the trustee is willing to violate the trustor's expectations [28]. The impact of blockchain is later argued to be mostly related to the oppression of possible opportunistic behavior, making the construct of opportunistic betrayal highly relevant.

In line with current findings [44, 52, 55], we argue that trust in the peer has a positive influence on the intention to transact (behavioral trusting intention). In 
peer-to-peer networks without an intermediary, we assume, that trust in the peer is vital, due to the lack of an intermediary, who could resolve or help in case of arising disputes. But trust in the platform plays a crucial role, too. Trust in the platform is regarded as a predictor of trust in the peer, because the (disintermediated) platform with blockchain and smart contracts at its core - needs to be trusted to even consider using the platform as user. Hence, trusting the peer and the products offered is dependent on the platform itself.

\subsection{Trust in platforms and intermediation}

Trust in the platform and its effects on peer, product and intention to transact can also be described with the three dimensions (beliefs) ability, integrity, and benevolence. The ability of a platform positively influences only window-shopping intentions, whereas integrity and benevolence affect purchase intention (intention to transact or trust related behavior) [33]. Ability describes whether the platform successfully matches transaction parties, processes transactions correctly and maintains a user-friendly interface. Especially secure and reliable data processing represents an important ability of a platform [44]. The platform's benevolence and integrity relates to the extent of user support, the amount of fees charged, truthful handling of payments, data privacy and security policies as well as authenticity and truthful display of all listed offerings. There can be multiple reason why platforms are threatened to lose trust, such as privacy concerns or scandals $[39,92]$.

When integrating the domains of lateral exchange markets and existing understandings of online trust, some key insights emerge on how the generation of trust in sharing platforms differs from traditional ecommerce contexts. It is proposed that the platform not only becomes an additional trust target, forming the distinct triad of interactions, but also incorporates the generation of institutional trust (institution-based trust) with its dimensions structural assurance and situation normality as depicted in figure 2 [62]. McKnight et al. [62] further include institution-based trust in a trust model, dealing with the trustor's perception of the online environment. It is related to the sociological conviction that the presence of structural conditions make the environment feel trustworthy and thereby facilitates the probability of successfully establishing trust-related beliefs and intentions in online interactions [62, 94]. As technology platforms in the sharing economy act as mediators between both market sides represented by private peers, they can be considered trustworthy or not in their ability to facilitate transactions $[46,72,75]$.
Structural assurances represents the trustor's beliefs that the interaction's success will be facilitated by the deployment of structures like guarantees, regulations or legal recourse [80, 94]. Situation normality deals with the trustor's beliefs that the environment is in a proper state, resulting in a high perceived interaction success rate since the environment is evaluated as favorable for positive transaction experiences [62]. Perceived trust in platforms can ultimately be described by the ability, benevolence and integrity of the platform within the dimensions structural assurances and situation normality [33].

Traditionally, institutions and organizations produced trust without previous interactions by deploying rules and exchange regulations based on legally binding contracts that are enforced by jurisdictions [23, 59, 94]. Today, the emergence of technology platforms has shifted the way we conduct business and how we consume. Based on network algorithms, lateral exchange markets have developed social networks with the capacity to mediate trust relationships [75]. The important trust effect of social capital arises in networks of like-minded people and leads to reciprocity, even without strong presence of traditional institutions in the network, also described as consociality [51, 67]. Digital infrastructure establishes digital connections between embedded individuals in a network and therefore facilitates the intensity of social interactions and exchange activities in the marketplace, while being more efficient and effective than institutional regulations and interventions [59, 66, 83]. The platform controls the digital infrastructure and social network.

Infrastructure and network of the platform is maintained through the dimension platform intermediation but operates on the dimension of consociality as a social operant resource between peers. In the model, an effect of institution-based trust on trust in peer is a function of consociality. It is proposed that the significance of trust towards the peers is generally influenced by the degree of consociality, whereas the importance of trust towards the platform is determined by the intensity of platform intermediation. This relationship is indicated in the proposed model, by linking platform intermediation to institution-based trust. To access the social capital accumulated by members and to ultimately facilitate interpersonal trust between peers and institutional trust, several mechanisms and designs have been deployed by technology platforms [67, 85]. Literature shows, that platform providers facilitate interpersonal trust, but are dependent on institutional trust itself to appear as a trustworthy institution, as well [66, 67]. With a high degree of platform intermediation, access platforms 
utilize the dimension structural assurances to further facilitate institutional-based trust. A positive effect of institutional structures on trust towards the trustee has been shown by Pavlou and Gefen [74] and McKnight et al. [63] in the e-commerce context. Furthermore, diverse literature has also expressed that trust between peers might be indeed strongly dependent on and influenced by structural assurances and intermediation deployed on peer-to-peer platforms [75, 86, 87]. Institutional trust therefore relies on underlying formal structures, processes, mechanisms and assurances that act as rules, securities and regulations to facilitate a belief in security of a situation or transaction on digital platforms [61, 74, 80, 94]. As a result, mechanisms deployed by the platform strengthen the consumer's belief that supplying peers have limited leeway for opportunistic betrayal, improving trust in the platform. In the model, institution-based trust has an effect on the peers that act on the platform, referring to the sociological systems-theoretic perspective of Luhmann [56] that personal trust between peers is embedded in system (infrastructure) trust (norms, rules and principles) [66, 81]. Trust-building measures increase the perceived trust of the platform itself because it appears as an environment that facilitates the success of interactions $[62,66]$.

In our model, trust in the platform, affected by the degree of platform intermediation, has an effect on trust in peers and trust in the product, while trust in peers is also mediated by consociality. The triad of trust targets in turn has an effect on the intention to transact.

\subsection{Trust in the product}

Trust in the product can be perceived as how reliable the product is evaluated by the potential consumer and how it is believed to fulfil its functions as understood by the consumer. [44, 46]. The relevance of the trust target product is generally acknowledged and it is argued that blockchain technology in combination with smart devices and internet of things can have a significant effect on trust generation. Interconnected and communicating products may demand even more trust in the infrastructure facilitating transactions with and among them. This infrastructure is represented by the institution transacting parties have to trust in.

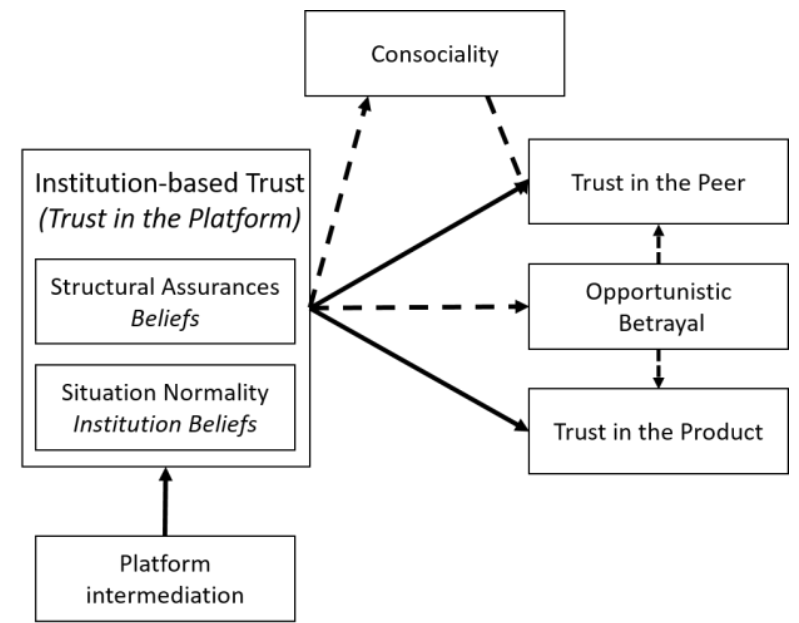

Figure 2. Proposed trust concept for institution based trust in the sharing economy

\section{Blockchain technology as trust building lever}

\subsection{Blockchain technology and smart contracts}

A blockchain can be described as a database or ledger that is distributed among its users. It enables them to transact value and ensure consensus via cryptographically secure and incentivized mechanisms - in a public or pseudonymous context - without depending on an intermediary or central authority to verify transactions [25, 37]. The best known implementation is Bitcoin [68], representing an electronic and peer-to-peer cash transaction system. However, the technology behind bitcoin, moves beyond its verification mechanism to a broader economic and commercial application spectrum [43]. With its most compelling characteristic of disintermediation, its potential is not tied to specific industries but allows for the design of tamper-resistant, distributed and transparent records of any form of value [15]. These attributes of blockchain technology are central for the proposed trust model and for applying the technology in the sharing economy to allow for disintermediated peer-to-peer transactions.

Smart contracts represent an important aspect of blockchain technology. They are programmable contracts, able to execute details of a contract according to the underlying code's logic [9]. Every smart contract can receive data and execute code based on the data it received. This way, smart contracts can also call other smart contracts, triggering each other. Due to its autonomous and immutable nature, no agent can tamper with the smart contract to alter its function to his benefit. A possible application field of smart contracts is the control and enforcement of ownership 
concerning properties and assets [69]. Blockchain technology can acts as the back-end of decentralized applications and distribute logic, instead of executing it on a centralized server [9]. As a result, blockchain technology and smart contracts allow conflicting or unfamiliar agents, who, to engage in transactions, omitting the intermediary. These transactions are cryptographically secured by providing a distributed software architecture and environment (a blockchainbased platform). Therefore, it removes the need for a centralized platform or authority represented by one organization [9, 89]. Due to its distributed nature, blockchain systems and smart contracts lack a potential single point of failure while providing a comprehensive, transparent and intrinsically valid log of the transaction history. Having such a proven history has the ability to resolve conflicts among transacting parties [43].

We suggest that the presence of blockchain technology affects trust at several stages and has the potential to solve trust issues in the sharing economy while at the same time facilitating disintermediation.

Blockchain technology changes how the economy interacts with ledgers, which in turn represent a significant mechanism for transactional legitimation and a core element of modern market capitalism [5, 70]. So far, the need for high-quality trusted ledgers translates into the need for central government institutions and large centralized aggregating organizations, which use centralized and trust-based ledger technologies, but depend on trust in their legitimacy and accuracy themselves to function properly [25]. Promising benefits of blockchain technology relate to the fundamental architectural change and organizational efficiency gains they introduce, potentially rendering trusted institutions and their layers of activities - like monitoring and regulating - obsolete $[18,25]$.

Blockchain technology also has drawbacks and limitations. Autonomous transactional systems are reliant on predefined rules which need to be secure, reliable and accurate from the beginning, since they cannot be changed afterwards due to their immutable characteristics [2, 43]. The immutable characteristics makes the accidental loss of resources through false transactions irretrievable [7]. The development of blockchain systems is still in its early stages and struggles with lacking scalability, query issues, high latency as well as rising costs and energy consumption associated with present consensus algorithms [9, 37, $71]$.

\subsection{Solving trust issues with blockchain}

The resolution of trust issues is regarded as one of the greatest promises of blockchain technology [37]. Being titled the trust machine, it is assumed to provide abilities that eliminate the need for centralized mechanisms that convey or signal trust, supposedly altering the way trust is built altogether [16, 27]. Figure 3 illustrates how the presence of blockchain technology mediates different aspects in the trust model.

Existing literature about the impact of blockchain technology on trust generally examines the capability to impose and enforce algorithmic rules and contractual agreements without a trusted central authority [43]. One of the most ambitious proposition in this regard are trust-free systems [40]. The idea is to use blockchain technology to generate a system that is governed by the system itself to resolve trust problems in peer-to-peer networks. In this theoretically trust-free context, the implementation of smart contracts for contractual agreements allows to omit expensive centralized mechanisms to build institutional trust or trust in peers by design [40, 43]. With blockchainbased reputation systems granting immutable information about the other party and smart contracts governing transaction details this seems possible. However, it is actually disputed if a blockchain-based system can be trust-free.

Experience with an object facilitates trust in that object [14, 56]. Accordingly, familiarity with blockchain technology is considered in a way that the effect of antecedents of trust on trust in the platform (institution-based trust) is moderated by familiarity with blockchain technology. In particular, the effect of manageable trust building levers (IT-artefacts) on trust in the platform is mediated by the presence of blockchain technology. The willingness to rely on blockchain technology the effect on trust of the platform might be dependent on the party's affinity to the technology itself [43]. Beck et al. [9] even state that trust in third parties is replaced by the understanding or familiarity of blockchain technology. If the disintermediated platform is based on blockchain technology, these effects should be considered.

In a study with bitcoin users, it was found that the need for trust shifts from central authorities to the algorithms that govern the interaction of blockchain users, questioning blockchain technology as a trust-free systems [43, 57]. Since smart contracts form the foundation of trust-free systems, they also need to be considered trust-free. A Smart contract can be considered trust-free if it fulfils the prerequisites of intelligibility, integrity over time and the absence of unilaterally manipulable data, yet $40 \%$ of all Ethereum-based smart contracts do not meet the latter prerequisite, suggesting the need for a securing third party [30]. Furthermore, a variety of sociotechnical 
factors, including the need for third party services, legal requirements, compliance with the existing institutional environment as well as transparency and clarity, seem essential for the user's trust towards a trust-building platform. [3, 43, 57]. It can therefore be assumed that intermediaries will still exist and be relevant for the generation of trust in a blockchainbased sharing economy. However, this does not imply that blockchain-based systems will not be able to subsidize intermediaries regarding certain aspects of the sharing economy. To account for different degrees of platform intermediation that might be needed, we argue that platform intermediation has an effect on trust of the platform. A variation of degree could be whether customer service or creation of smart contracts might still be supplied by an organization as intermediary, for example.

The presence of blockchain technology also is expected to have an effect on trust in peers and trust in products, because blockchain technology could verify peer identities, their reputation or authenticity of products to prevent fraud.

Following the model of Gefen and Straub [36] as well as McKnight et al. [62], the suggested triad of trust targets, we argue that opportunism (opportunistic betrayal) and the measurement of trust are an integrated construct. If presence of blockchain technology limits the possibilities for expected opportunistic betrayal in an online transaction, with its programmable, public and immutable nature and smart contracts, then the trust dimensions of integrity and benevolence are expected to increase [28, 64]. The level of trust in the platform (institution-based trust) and hence - mediated by opportunistic betrayal - trust in the peers is expected to be positively affected.

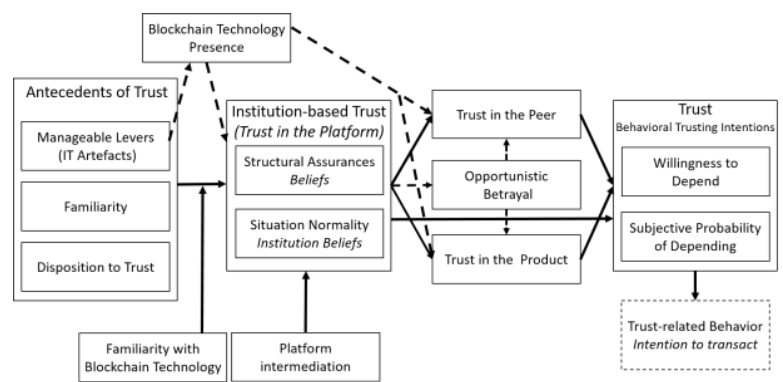

Figure 3. Trust model with blockchain technology

\section{Discussion}

\subsection{Theoretical implications}

If blockchain technology would allow for trust-free transactions, transaction cost theory and principal agent theory would be affected. This is due to the fact that the lack of trust and possibly differentiating interests form the basis for both theories, examining consequences for involved actors and organizations $[21,48]$. Blockchain-based systems would give way to a new economy in form of collaborative, cryptographic and internet-based environments with decentralized autonomous organization, which operate trust-free through transactions based on self-enforcing rules [6, $8,9]$. As a result, blockchain technology is argued to substantially reduce transaction costs by more efficiently coordinating economic activities compared to hierarchies (which utilize incomplete contracts to tackle opportunism) and relational contracting (which needs trust between parties and reoccurring interactions) [25]. This superior efficiency stems from the fact that firms primarily consist of incomplete contracts, which are associated with increased costs due to information problems, cost of writing contracts and necessary contract enforcement [41, 42, 48]. Blockchain technology does not overcome opportunism but rather suppresses opportunism at a cost to a third party. Namely, the party that ensures consensus via some consensus mechanism and through radical public transparency or enforcement with smart contracts $[12,84]$.

Using blockchain technology as a platform for transactions affects the principal agent dilemma. With blockchain-based systems, the task or agreement could be coded into a smart contract, so each part of the transaction can be monitored and executed with certainty if the conditions relevant to the principle are met, possible reducing the principle agent dilemma (the principal acting only in his own best interest) by mitigating information asymmetry between transacting parties and limiting moral hazard [6]. Hence, blockchain technology might not only facilitate the generation of trust, but is also able to monitor itself, making the need for non-market monitoring mechanisms introduced by Alchian and Demsetz [4] potentially unnecessary [25]. Nevertheless, blockchain technology may substitute classic institutional activities - where complete contracts can be deployed viably - but it will not replace existing institutions entirely. Qualitative and Quantitative research can help identify to which extent platform intermediation is necessary or desired by platform users when blockchain technology is present for building trust.

\subsection{Practical implications}

The model enables researchers to study the effect of blockchain technology on trust in the sharing economy. Results can help organizations to decide how to make the best use out of the nascent technology regarding strategic and organizational decisions. Depending on 
how viable disintermediation is and to which degree blockchain technology affects trust in the intermediating platform, a possible disruption by blockchain technology can be predicted.

Also, the model might help to prove that blockchain technology provides means to build trust more cheaply and even extends the creation of trust, because blockchain technology can limit opportunism where it has not been possible or viable before; such as in peer-to-peer transactions. There are several trustbuilding, blockchain-based mechanism conceivable, such as personal identification or reputation systems stored on blockchains, lowering transaction costs and allowing users to measure and increase their level of trust in other users or the platform [43]. Blockchainbased systems provide means to facilitate trust in transaction-intensive contexts, eroding the margin of institutional efficiency and shift it towards markets [18]. However, in order to interact securely with this new party to a transaction, a traditional intermediary may still be needed in the near future and people will need to become more familiar with the new technology. But the idea of blockchain technology decentralizing intermediary and trust-building services in the sharing economy is generally supported by Glaser [37] and Hawlitschek et al. [43].

The authors argue that these systems might only work in the context of closed peer-to-peer platforms for now. Because smart contacts can be regarded as complete contracts, blockchain technology might not compete head-to-head with firms, but replace services of existing organizations where complete contracts can be implemented instead of incomplete contracts. This means, it may become the preferred underlying platform for transactions where opportunism exists. Still, a certain degree of control by an organization when implementing private blockchains could be feasible or desired [25, 91]. Due to the limitations of blockchains to govern real-life opportunistic behavior, it is proposed that blockchains only suppress opportunism to a certain extend instead of eliminating it entirely [43].

\section{References}

[1] Agarwal, R. and J. Prasad, "A Conceptual and Operational Definition of Personal Innovativeness in the Domain of Information Technology", Information systems research, 9(2), 1998, pp. 204-215.

[2] Ahangama, S. and D.C.C. Poo, "Credibility of Algorithm Based Decentralized Computer Networks Governing Personal Finances: The Case of Cryptocurrency", International Conference on HCI in Business, Government and Organizations, 2016, pp. 165-176.
[3] Al Khalil, F., T. Butler, L. O'Brien, and M. Ceci, Trust in Smart Contracts is a Process, As Well, 2017.

[4] Alchian, A.A. and H. Demsetz, "Production, information costs, and economic organization", The American economic review, 62(5), 1972, pp. 777-795.

[5] Allen, D., The Institutional Revolution, University of Chicago Press, Chicago, 2011.

[6] Avital, M., R. Beck, J. King, M. Rossi, and R. Teigland, "Jumping on the Blockchain Bandwagon: Lessons of the Past and Outlook to the Future", 2016.

[7] Barber, S., X. Boyen, E. Shi, and E. Uzun, "Bitter to better-how to make bitcoin a better currency", International Conference on Financial Cryptography and Data Security, 2012, pp. 399-414.

[8] Beck, R., M. Avital, M. Rossi, and J.B. Thatcher, "Blockchain Technology in Business and Information Systems Research", Business \& Information Systems Engineering, 59(6), 2017, pp. 381-384.

[9] Beck, R., J.S. Czepluch, N. Lollike, and S. Malone, "Blockchain-the Gateway to Trust-Free Cryptographic Transactions", Research Papers, 153, 2016.

[10] Belk, R., "Sharing versus pseudo-sharing in Web 2.0", The Anthropologist, 18(1), 2014, pp. 7-23.

[11] Belk, R., "You are what you can access: Sharing and collaborative consumption online", Journal of Business Research, 67(8), 2014, pp. 1595-1600.

[12] Berg, C., S. Davidson, and J. Potts, "Blockchains industrialise trust", 2017.

[13] Bigley, G.A. and J.L. Pearce, "Straining for shared meaning in organization science: Problems of trust and distrust", Academy of management review, 23(3), 1998, pp. 405-421.

[14] Blau, P., Exchange and power in social life, Routledge, 2017.

[15] Böhme, R., N. Christin, B. Edelman, and T. Moore, "Bitcoin: Economics, technology, and governance", Journal of Economic Perspectives, 29(2), 2015, pp. 213-238.

[16] Botsman, R., Who Can You Trust?: How Technology Brought Us Together and Why It Might Drive Us Apart, PublicAffairs, New York, 2017.

[17] Butler Jr, J.K., "Toward understanding and measuring conditions of trust: Evolution of a conditions of trust inventory", Journal of management, 17(3), 1991, pp. 643663.

[18] Catalini, C. and J.S. Gans, Some simple economics of the blockchain, National Bureau of Economic Research, 2016.

[19] Chai, S., S. Das, and H.R. Rao, "Factors affecting bloggers' knowledge sharing: An investigation across gender", Journal of Management Information Systems, 28(3), 2011, pp. 309-342.

[20] Chesley, D.L., Trust, but verify: why it matters in the sharing economy, 2016.

[21] Coase, R.H., "The nature of the firm", economica, 4(16), 1937, pp. 386-405.

[22] Coleman, J.S., "Social capital in the creation of human capital", in Knowledge and social capital. 2000. Elsevier. 
[23] Cook, K.S., R. Hardin, and M. Levi, Cooperation without trust?, Russell Sage Foundation, 2005.

[24] Corbitt, B.J., T. Thanasankit, and H. Yi, "Trust and ecommerce: a study of consumer perceptions", Electronic Commerce Research and Applications, 2(3), 2003, pp. 203 215.

[25] Davidson, S., P. de Filippi, and J. Potts, "Blockchains and the economic institutions of capitalism", Journal of Institutional Economics, 2018, pp. 1-20.

[26] Dwyer, F.R., P.H. Schurr, and S. Oh, "Developing buyer-seller relationships", The Journal of marketing, 1987, pp. 11-27.

[27] Economist, T., "The promise of the blockchain: The trust machine'", The Economist, 31, 2015.

[28] Elangovan, A.R. and D.L. Shapiro, "Betrayal of trust in organizations", Academy of management review, 23(3), 1998, pp. 547-566.

[29] Filippi, P. de, "What Blockchain Means for the Sharing Economy", Harvard Business Review Digital Articles., 15, 2017, p. 2017.

[30] Fröwis, M. and R. Böhme, "In Code We Trust?", in Data Privacy Management, Cryptocurrencies and Blockchain Technology. 2017. Springer.

[31] Ganesan, S., "Determinants of long-term orientation in buyer-seller relationships", The Journal of marketing, 1994, pp. 1-19.

[32] Gefen, D., "E-commerce: the role of familiarity and trust", Omega, 28(6), 2000, pp. 725-737.

[33] Gefen, D., "Customer loyalty in e-commerce", Journal of the association for information systems, 3(1), 2002, p. 2.

[34] Gefen, D., "Reflections on the dimensions of trust and trustworthiness among online consumers", ACM SIGMIS Database: the DATABASE for Advances in Information Systems, 33(3), 2002, pp. 38-53.

[35] Gefen, D., I. Benbasat, and P. Pavlou, "A research agenda for trust in online environments", Journal of Management Information Systems, 24(4), 2008, pp. 275286.

[36] Gefen, D. and D.W. Straub, "Consumer trust in B2C eCommerce and the importance of social presence: experiments in e-Products and e-Services", Omega, 32(6), 2004, pp. 407-424.

[37] Glaser, F., "Pervasive decentralisation of digital infrastructures: a framework for blockchain enabled system and use case analysis", 2017.

[38] Gounaris, S. and S. Dimitriadis, "Assessing service quality on the web: evidence from business-to-consumer portals", Journal of Services Marketing, 17(5), 2003, pp. 529-548.

[39] Gregg, D.G. and S. Walczak, "The relationship between website quality, trust and price premiums at online auctions", Electronic Commerce Research, 10(1), 2010, pp. 1-25.

[40] Greiner, M. and H. Wang, "Trust-free systems-a new research and design direction to handle trust-issues in $\mathrm{P} 2 \mathrm{P}$ systems: the case of Bitcoin", 2015.

[41] Hart, O., "An Economist's Perspective on the Theory of the Firm", Columbia law review, 89(7), 1989, pp. 17571774.
[42] Hart, O. and J. Moore, "Property Rights and the Nature of the Firm", Journal of political Economy, 98(6), 1990, pp. 1119-1158.

[43] Hawlitschek, F., B. Notheisen, and T. Teubner, "The limits of trust-free systems: A literature review on blockchain technology and trust in the sharing economy", Electronic Commerce Research and Applications, 2018.

[44] Hawlitschek, F., T. Teubner, M.T.P. Adam, N.S. Borchers, M. Moehlmann, and C. Weinhardt, "Trust in the sharing economy: An experimental framework", Conference: Conference: International Conference on Information Systems (ICIS), 37, 2016.

[45] Hawlitschek, F., T. Teubner, and H. Gimpel, "Understanding the Sharing Economy - Drivers and Impediments for Participation in Peer-to-Peer Rental", Proceedings of the 49th Hawaii International Conference on System Sciences (HICSS), 2016.

[46] Hawlitschek, F., T. Teubner, and C. Weinhardt, "Trust in the sharing economy", Die Unternehmung, 70(1), 2016, pp. 26-44.

[47] Hosmer, L.T., "Trust: The connecting link between organizational theory and philosophical ethics", Academy of management review, 20(2), 1995, pp. 379-403.

[48] Jensen, M.C. and W.H. Meckling, "Theory of the firm: Managerial behavior, agency costs and ownership structure", Journal of financial economics, 3(4), 1976, pp. 305-360.

[49] Karahanna, E., D.W. Straub, and N.L. Chervany, "Information technology adoption across time: a crosssectional comparison of pre-adoption and post-adoption beliefs", MIS quarterly, 1999, pp. 183-213.

[50] Koopman, C., M. Mitchell, and A. Thierer, "The sharing economy and consumer protection regulation: The case for policy change", J. Bus. Entrepreneurship \& L., 8, 2014, p. 529.

[51] Kramer, R.M., M.B. Brewer, and B.A. Hanna, "Collective trust and collective action", Trust in organizations: Frontiers of theory and research, 1996, pp. 357-389.

[52] Leonard, L.N.K., "Attitude influencers in C2C ecommerce: Buying and selling", Journal of Computer Information Systems, 52(3), 2012, pp. 11-17.

[53] Lessig, L., Remix: Making art and commerce thrive in the hybrid economy, Penguin, 2008.

[54] Lu, J., L. Wang, and L.A. Hayes, "How do technology readiness, platform functionality and trust influence $\mathrm{C} 2 \mathrm{C}$ user satisfaction?", Journal of Electronic Commerce Research, 13(1), 2012, p. 50.

[55] Lu, Y., L. Zhao, and B. Wang, "From virtual community members to $\mathrm{C} 2 \mathrm{C}$ e-commerce buyers: Trust in virtual communities and its effect on consumers' purchase intention", Electronic Commerce Research and Applications, 9(4), 2010, pp. 346-360.

[56] Luhmann, N., Trust and power, John Wiley \& Sons, 2018.

[57] Lustig, C. and B. Nardi, "Algorithmic authority: The case of Bitcoin", Proceedings of the 48th Hawaii International Conference on System Sciences (HICSS), 2015, pp. $743-752$. 
[58] Mayer, R.C., J.H. Davis, and F.D. Schoorman, "An integrative model of organizational trust", Academy of management review, 20(3), 1995, pp. 709-734.

[59] Mazzella, F., A. Sundararajan, V.B. D'Espous, and M. Möhlmann, "How Digital Trust Powers the Sharing Economy", IESE Insight(30), 2016, pp. 24-31.

[60] McAllister, D.J., "Affect-and cognition-based trust as foundations for interpersonal cooperation in organizations", Academy of management journal, 38(1), 1995, pp. 24-59.

[61] McKnight, D.H. and N.L. Chervany, "What trust means in e-commerce customer relationships: An interdisciplinary conceptual typology", International journal of electronic commerce, 6(2), 2001, pp. 35-59.

[62] McKnight, D.H., V. Choudhury, and C. Kacmar, "Developing and validating trust measures for e-commerce: An integrative typology", Information systems research, 13(3), 2002, pp. 334-359.

[63] McKnight, D.H., V. Choudhury, and C. Kacmar, "The impact of initial consumer trust on intentions to transact with a web site: a trust building model", The journal of strategic information systems, 11(3-4), 2002, pp. 297-323.

[64] McKnight, D.H., L.L. Cummings, and N.L. Chervany, "Initial trust formation in new organizational relationships", Academy of management review, 23(3), 1998, pp. 473-490.

[65] Möhlmann, M., "Collaborative consumption: determinants of satisfaction and the likelihood of using a sharing economy option again", Journal of Consumer Behaviour, 14(3), 2015, pp. 193-207.

[66] Möhlmann, M., "Digital trust and peer-to-peer collaborative consumption platforms: A mediation analysis", 2016.

[67] Möhlmann, M. and A. Geissinger, Trust in the sharing economy: Platform-Mediated Peer Trust, Cambridge University Press, Cambridge, 2018.

[68] Nakamoto, S., "Bitcoin: A peer-to-peer electronic cash system", 2008.

[69] Nofer, M., P. Gomber, O. Hinz, and D. Schiereck, "Blockchain", Business \& Information Systems Engineering, 59(3), 2017, pp. 183-187.

[70] Nussbaum, F.L., History of the Economic Institutions of Modern Europe, Crofts, New York, 1933.

[71] O'Dwyer, K.J. and D. Malone, "Bitcoin mining and its energy footprint", 2014.

[72] Parker, G.G. and M.W. van Alstyne, "Two-sided network effects: A theory of information product design", Management Science, 51(10), 2005, pp. 1494-1504.

[73] Pavlou, P.A. and M. Fygenson, "Understanding and predicting electronic commerce adoption: An extension of the theory of planned behavior", MIS quarterly, 2006, pp. 115-143.

[74] Pavlou, P.A. and D. Gefen, "Building effective online marketplaces with institution-based trust", Information systems research, 15(1), 2004, pp. 37-59.

[75] Perren, R. and R.V. Kozinets, "Lateral Exchange Markets: How Social Platforms Operate in a Networked Economy", Journal of Marketing, 82(1), 2018, pp. 20-36.

[76] Putnam, R.D., "Bowling alone: America's declining social capital", in Culture and politics. 2000. Springer.
[77] Rousseau, D.M., S.B. Sitkin, R.S. Burt, and C. Camerer, "Not so different after all: A cross-discipline view of trust", Academy of management review, 23(3), 1998, pp. 393-404.

[78] Schilke, O. and K.S. Cook, "Sources of alliance partner trustworthiness: Integrating calculative and relational perspectives", Strategic Management Journal, 36(2), 2015, pp. 276-297.

[79] Schurr, P.H. and J.L. Ozanne, "Influences on exchange processes: Buyers' preconceptions of a seller's trustworthiness and bargaining toughness", Journal of consumer research, 11(4), 1985, pp. 939-953.

[80] Shapiro, S.P., "The social control of impersonal trust", American journal of Sociology, 93(3), 1987, pp. 623-658.

[81] Stewart, K.J., "Trust transfer on the world wide web", Organization Science, 14(1), 2003, pp. 5-17.

[82] Strader, T.J. and S.N. Ramaswami, "The value of seller trustworthiness in $\mathrm{C} 2 \mathrm{C}$ online markets", Communications of the ACM, 45(12), 2002, pp. 45-49.

[83] Sundararajan, A., The sharing economy: The end of employment and the rise of crowd-based capitalism, Mit Press, 2016.

[84] Swanson, T., Great Chain of Numbers, Creative Commons, 2014.

[85] Teubner, T., "Thoughts on the sharing economy", Proceedings of the International Conference on e-Commerce, 11, 2014, pp. 322-326.

[86] Teubner, T. and F. Hawlitschek, "The economics of P2P online sharing", The Sharing Economy: Possibilities, Challenges, and the way forward, Praeger Publishing, 2017.

[87] Teubner, T., F. Hawlitschek, and D. Dann, "Price determinants on Airbnb: How reputation pays off in the sharing economy", Journal of Self-Governance \& Management Economics, 5(4), 2017, pp. 53-80.

[88] Venkatesh, V. and F.D. Davis, "A theoretical extension of the technology acceptance model: Four longitudinal field studies", Management Science, 46(2), 2000, pp. 186-204.

[89] Weber, I., X. Xu, R. Riveret, G. Governatori, A. Ponomarev, and J. Mendling, "Untrusted business process monitoring and execution using blockchain", International Conference on Business Process Management, 2016, pp. 329-347.

[90] Weber, T.A., "Intermediation in a Sharing Economy: Insurance, Moral Hazard, and Rent Extraction", Journal of Management Information Systems, 31(3), 2014, pp. 35-71.

[91] Wright, A. and P. de Filippi, "Decentralized blockchain technology and the rise of lex cryptographia", 2015.

[92] Yoon, H.S. and L.G. Occeña, "Influencing factors of trust in consumer-to-consumer electronic commerce with gender and age", International Journal of Information Management, 35(3), 2015, pp. 352-363.

[93] Zand, D.E., "Trust and managerial problem solving", Administrative science quarterly, 1972, pp. 229-239.

[94] Zucker, L.G., "Production of trust: Institutional sources of economic structure, 1840-1920", Research in organizational behavior, 1986. 